\title{
PENYUSUNAN BLUEPRINT INFRASTRUKTUR JARINGAN KOMPUTER MENGGUNAKAN ANALISIS SWOT PADA STMIK LOMBOK
}

\author{
Ahmad Tantoni', Mohammad Taufan Asri Zaen² \\ ${ }^{1}$ Program Studi Teknik Informatika, STMIK Lombok \\ 2Program Studi Sistem Informasi, STMIK Lombok \\ Jln. Basuki Rahmat No.105 Praya Lombok Tengah 83511 \\ 1 ahmad.tantoni@students.amikom.ac.id, 20panzain@gmail.com
}

\begin{abstract}
College is an institution that has quite complex elements, between elements is always exchanging data, has a strong enough communication so it is suitable for applying information technology. As a private tertiary institution, STMIK Lombok, in Praya, Central Lombok, is also developing information technology strategies.

To compile an information technology strategy from a business strategy in building a computer network infrastructure, an analysis of strategy is needed in its preparation. Information technology strategy development will use a SWOT analysis that will analyze the internal and external environment. SWOT analysis is also a systematic identification of various factors for formulating organizational strategies. This study discusses the preparation of a Computer Network Infrastructure Blueprint using SWOT Analysis at STMIK Lombok.

The SWOT analysis is expected to be able to offer/give a comprehensive picture in the compilation of the Computer Network Infrastructure Blueprint as response about the needs of stakeholders in planning sustainable development at STMIK Lombok.
\end{abstract}

Keywords: Blueprint, SWOT analysis, SI / IT, Infrastructure, Computer Networks

\begin{abstract}
Abstrak
Perguruan tinggi merupakan institusi yang memiliki elemen cukup kompleks, antar elemen selalu bertukar data, memiliki komunikasi cukup kuat sehingga sangat cocok untuk menerapkan teknologi informasi. Sebagai sebuah perguruan tinggi swasta, STMIK Lombok yang berlokasi di Praya Lombok Tengah juga melakukan pengembangan strategi teknologi informasi.

Untuk menyusun strategi teknologi informasi dari strategi bisnis dalam membangun infrastruktur jaringan komputer diperlukan sebuah analisis strategi dalam penyusunannya. Penyusunan strategi teknologi informasi akan menggunakan analisis SWOT yang akan menganalisis lingkungan internal dan eksternal. Analisis SWOT juga merupakan identifikasi berbagai faktor secara sistematis untuk merumuskan strategi organisasi. Penelitian ini membahas penyusunan Blueprint Infrastruktur Jaringan Komputer menggunakan Analisis SWOT di STMIK Lombok.

Analisis SWOT ini diharapkan mampu memberikan gambaran menyeluruh dalam penyusunan Blueprint Infrastruktur Jaringan Komputer sebagai masukan mengenai kebutuhan kepada stakeholders dalam pembangunan berkelanjutan yang terencana di STMIK Lombok
\end{abstract}

Kata kunci: Blueprint, analisis SWOT, SI/TI, Infrastruktur, Jaringan Komputer 


\section{PENDAHULUAN}

Menurut Jogiyanto dan Abdillah [1] secara prinsip, teknologi informasi (TI) telah menjadi pemungkin (enabler) bagi organisasi dalam rangka mencapai tujuan. Oleh sebab itu kehadiran TI menjadi suatu yang penting bagi organisasi. Selain itu, invertasi TI diperusahaan relatif besar, terlebih pada perusahaan yang intensitas pengandalan teknologi informasinya tinggi.

Perguruan tinggi merupakan salah satu contoh institusi yang memiliki elemen cukup kompleks, antar elemen selalu bertukar data memiliki komunikasi cukup kuat sehingga sangat cocok untuk menerapkan teknologi informasi. [2]

STMIK Lombok merupakan sebuah PTS yang berada di kabupaten Lombok Tengah dan STMIK Lombok juga menjadikan pengembangan strategi SI/TI.

Dalam penyusunan strategi teknologi informasi dari strategi bisnis untuk membangun infrastruktur jaringan komputer, diperlukan juga sebuah analisis strategi dalam penyusunannya. Menurut Sadewo [3] untuk penyusunan strategi teknologi informasi menggunakan analisis SWOT akan menganalisis lingkungan internal yang sangat berpengaruh dan menentukan perencanaan strategi yang akan diformulasikan, sedangkan menganalisis lingkungan eksternal yang berada diluar kendali organisasi harus dipertimbangkan dalam penentuan strategi. Rangkuti juga menambahkan, analisis SWOT merupakan identifikasi berbagai faktor secara sistematis untuk merumuskan strategi organisasi [4]. Dari latar belakang ini, maka dilakukan penelitian mengenai Penyusunan Blueprint Infrastruktur Jaringan Komputer Menggunakan Analisis SWOT pada STMIK Lombok.

\section{PUSTAKA DAN TEORI}

\section{A. Tinjauan Pustaka}

Penelitian yang dilakukan Nisak tentang analisis SWOT untuk menentukan strategi kompetitif. Permasalahan apakah analisis SWOT merupakan stratergi yang tepat guna meningkatkan produksi pada perushaan dan bagimana strategi kompetitif yang di terapkan perusahaan dalam mengatasi persainggan global. Metode penyelesaian menggunakan jenis penelitian kualitatif dengan pendekatan deskriptif yaitu sebuah penelitian yang bertujuan membuat pencandraan secara sistematis, faktual dan akurat mengenai fakta- fakta dan sifat-sifat obyek penelitian. Hasil penelitian dengan menggunakan analisis SWOT, yaitu IFAS, IFAS dan matrik SWOT mempunyai posisi yang sangat strategis untuk mendukung perkembangan memperoleh keunggulan strategi. [5]

Penelitian yang dilakukan Noor (2014) tentang analisis SWOT dalam menentukan strategi pemasaran Daihatsu Luxio di Malang (Studi Kasus Pada PT. Astra International Tbk. Daihatsu Malang). Permasalahan adalah peluang pasar yang besar maka diperlukan suatu strategi pemasaran Daihatsu Luxio yang dapat meningkatkan pangsa pasar Daihatsu Luxio dengan memaksimalkan kekuatan dan peluang yang dimiliki oleh Daihatsu Luxio serta meminimalkan kelemahan dan ancaman yang dimiliki. Dengan kriteria tersebut maka analisis SWOT adalah metode yang tepat. Metode penyelesaian meliputi data primer dalam penelitian ini dihasilkan melalui kuesioner dan wawancara terhadap karyawan. Data sekunder dalam penelitian ini diperoleh dari studi pustaka dan data dokumenter. Hasil penelitian menunjukkan bahwa posisi produk berada pada koordinat 3,582 dan 3,551. Koordinat tersebut terletak pada kuadran I yang mendukung strategi pertumbuhan dengan konsentrasi melalui integrasi vertikal. Dari matrik SWOT dapat kita lihat strategi- strategi yang dapat diterapkan untuk meningkatkan pemasaran dan volume penjualan Daihatsu Luxio yaitu meningkatkan hubungan kerjasama dengan pihak bank dan leasing, menjaga dan meningkatkan kualitas pelayanan serta sumber daya perusahaan. [6]

\section{B. Analisis SWOT}

Analisis SWOT (Strenght, Weakness, Opportunity, Threat) merupakan alat identifikasi berbagai faktor yang digunakan dalam perumusan strategi perusahaan [7]. Analisis ini didasarkan pada logika yang dapat memaksimalkan kekuatan (Strenght) dan peluang (Opportunity), namun secara bersamaan dapat meminimalkan kelemahan (Weakness) dan ancaman (Threat). Analisis SWOT hanya menggambarkan situasi yang terjadi dan bukan sebagai pemecah masalah.

Analisis SWOT dapat digambarkan menjadi suatu matriks disebut matriks SWOT. Matriks ini dapat menggambarkan secara jelas bagaimana peluang dan ancaman eksternal yang dihadapi organisasi dapat sesuai dengan kekuatan dan 
kelemahan yang dimiliki organisasi. Empat kemungkinan alternatif stratgis yang diperoleh dari Matriks SWOT, yaitu:

- Strategi S-0: Strategi ini dibuat dengan menggabungkan seluruh kekuatan untuk merebut dan memanfaatkan peluang sebesarbesarnya.

- Strategi S-T: Strategi ini dibuat dengan menggabungkan seluruh kekuatan organisasi dalam mengawasi ancaman.

- Strategi W-0: Strategi ini ditetapkan berdasarkan pemanfaatan peluang yang muncul dengan meminimalkan kelemahan yang ada.

- Strategi W-T: Strategi ini didasarkan pada kegiatan yang bersifat defensif dan berusaha meminimalkan kelemahan yang ada serta menghadiri ancaman.

Tabel 1. Matriks SWOT

\begin{tabular}{|c|c|c|}
\hline Ekternal & $\begin{array}{l}\text { Kekuatan } \\
\text { (Strenght) }\end{array}$ & $\begin{array}{l}\text { Kelemahan } \\
\text { (Weakness) }\end{array}$ \\
\hline $\begin{array}{c}\text { Peluang } \\
\text { (Opportunity) }\end{array}$ & $\begin{array}{l}\text { Strategi S-O } \\
\text { Strategi yang } \\
\text { menggunakan } \\
\text { kekuatan } \\
\text { untuk } \\
\text { memanfaatkan } \\
\text { peluang }\end{array}$ & $\begin{array}{l}\text { Strategi W-0 } \\
\text { Strategi yang } \\
\text { meminimalkan } \\
\text { kelemahan } \\
\text { untuk } \\
\text { memanfatkan } \\
\text { peluang. }\end{array}$ \\
\hline $\begin{array}{c}\text { Ancaman } \\
\text { (Threat) }\end{array}$ & $\begin{array}{l}\text { Strategi S-T } \\
\text { Strategi yang } \\
\text { menggunakan } \\
\text { kekuatan } \\
\text { untuk } \\
\text { mengawasi } \\
\text { ancaman }\end{array}$ & $\begin{array}{l}\text { Strategi W-T } \\
\text { Strategi yang } \\
\text { meminimalkan } \\
\text { kelemahan } \\
\text { dan } \\
\text { menghindari } \\
\text { ancaman } \\
\end{array}$ \\
\hline
\end{tabular}

Menurut Rangkuti [4] Analisis SWOT membandingkan antara faktor eksternal yaitu peluang dan ancaman dengan faktor internal yaitu kekuatan dan kelemahan. Sebelum strategi diterapkan, perencana strategi harus menganalisis lingkungan eksternal untuk mengetahui berbagai kemungkinan peluang dan ancaman. Masalah strategis yang akan dimonitor harus ditentukan karena masalah ini mungkin dapat mempengaruhi perusahaan dimasa yang akan datang.

Menurut Rangkuti [4] Analisis SWOT membandingkan antara faktor eksternal peluang (opportunities) dan ancaman (threats) dengan faktor internal kekuatan (strengths) dan kelemahan (weaknesses).

Analisis SWOT membandingkan antara faktor eksternal peluang dan ancaman dengan faktor internal kekuatan dan kelemahan. Faktor internal dimasukan kedalam matrik yang disebut matrik faktor strategi internal atau IFAS (Internal Strategic Factor Analisis Summary). Faktor eksternal dimasukkan kedalam matrik yang disebut matrik faktor strategi eksternal EFAS (Eksternal Strategic Factor Analisis Summary).

Setelah matrik faktor strategi internal dan eksternal selesai disusun, kemudian hasilnya dimasukkan dalam model kuantitatif, yaitu matrik SWOT untuk merumuskan strategi kompetitif perusahaan. [4]

Tabel 2. Matrik Factor Strategi Eksternal (EFAS)

\begin{tabular}{|l|c|c|c|c|}
\hline $\begin{array}{c}\text { Faktor } \\
\text { Strategi } \\
\text { Eksternal }\end{array}$ & Bobot & Rating & $\begin{array}{c}\text { Bobot } \\
\text { X } \\
\text { Rating }\end{array}$ & $\begin{array}{c}\text { Keteran } \\
\text { gan }\end{array}$ \\
\hline Peluang & $\mathrm{X}$ & $\mathrm{X}$ & $\mathrm{X}$ & \\
\hline Jumlah & $\mathrm{X}$ & $\mathrm{X}$ & $\mathrm{X}$ & \\
\hline Ancaman & $\mathrm{X}$ & $\mathrm{X}$ & $\mathrm{X}$ & \\
\hline Jumlah & $\mathrm{X}$ & $\mathrm{X}$ & $\mathrm{X}$ & \\
\hline Total & $\mathrm{X}$ & $\mathrm{X}$ & $\mathrm{X}$ & \\
\hline
\end{tabular}

Tabel 3. Matrik Faktor Strategi Internal (IFAS)

\begin{tabular}{|l|c|c|c|c|}
\hline $\begin{array}{c}\text { Faktor } \\
\text { Strategi } \\
\text { Internal }\end{array}$ & Bobot & Rating & $\begin{array}{c}\text { Bobot } \\
\mathrm{X} \\
\text { Rating }\end{array}$ & $\begin{array}{c}\text { Keteran } \\
\text { gan }\end{array}$ \\
\hline Kekuatan & $\mathrm{X}$ & $\mathrm{X}$ & $\mathrm{X}$ & \\
\hline Jumlah & $\mathrm{X}$ & $\mathrm{X}$ & $\mathrm{X}$ & \\
\hline Kelemahan & $\mathrm{X}$ & $\mathrm{X}$ & $\mathrm{X}$ & \\
\hline Jumlah & $\mathrm{X}$ & $\mathrm{X}$ & $\mathrm{X}$ & \\
\hline Total & $\mathrm{X}$ & $\mathrm{X}$ & $\mathrm{X}$ & \\
\hline
\end{tabular}

\section{METODOLOGI PENELITIAN}

Metode yang digunakan adalah action research dengan mempersiapkan analisis kebutuhan infrastruktur jaringan komputer seperti kebutuhan sistem informasi, kebutuhan infrastruktur jaringan komputer, kebutuhan user dan penyelarasan strategi TI dari strategi bisnis STMIK Lombok. Kuisioner diberikan kepada Ketua Yayasan, Ketua Lembaga, Puket I, Puket II, Puket III, Kepala LPPM, BAAK, KaProdi TI, KaProdi SI, Kepala Pustik. 


\section{Hasil dan Pembahasan}

Berikut Hasil faktor-faktor internal (strenght-weakness) dan external (opportunitythreat) menggunakan analisis SWOT :

\section{A. Strength - Kekuatan sebagai berikut:}

1. Adanya komitmen yayasan dalam alokasi dana untuk meningkatkan pengembangan jaringan komputer.

2. Adanya komitmen yayasan dalam alokasi dana untuk pembangunan gedung.

3. Sistem informasi yang sudah berjalan sebanyak 5 sistem informasi yaitu website kampus, SI-akademik, SI-Keuangan, SI-PMB dan SI-E-learning.

4. Adanya unit khusus yang menangani sistem informasi.

5. Adanya website kampus stmiklombok.ac.id dengan server sendiri.

6. Adanya infrastruktur hardware jaringan yang sedang digunakan saat ini.

7. Arah pelayanan yang berbasis teknologi informasi.

8. Ruang laboratorium dilengkapai dengan AC, LCD dan internet.

9. Adanya kerjasama dengan pemerintah daerah dan industri di wilayah Lombok Tengah dalam hal pendanaan.

\section{B. Weakness - Kelemahan sebagai berikut:}

1. Infrastruktur jaringan komputer masih tradisional seperti belum diterapkannya model hirarki desain jaringan.

2. Belum menerapkan teknologi jaringan komputer terbaru seperti VLAN (Virtual LAN)

3. Tidak tersedianya perangkat keamanan jaringan komputer seperti firewall, IDS, IPS.

4. Jumlah access point masih kurang.

5. Tidak tersedianya fasilitas komputer dikelas dan fasilitas untuk akses internet untuk komputer kelas.

6. Sistem Informasi yang sedang dikembangkan sebanyak 10 sistem informasi.

7. Jumlah komputer pada lab komputer masih belum memadai.

8. Implementasi sistem informasi belum teritegrasi dan masih belum optimal.

9. Masih kurangnya gedung perkuliahan

10. Belum ada ruangan khusus untuk ruang Server.

11. Jumlah ruang laboratorium hanya 1 dan masih membutuhkan banyak ruang laboratorium.

\section{Opportunity - Peluang sebagai berikut:}

1. Perkembangan teknologi informasi sangat cepat terutama pada perkembangan teknologi jaringan komputer.

2. Adanya dukungan yayasan untuk meningkatkan pengembangan infrastruktur jaringan komputer dan penambahan jumlah komputer.

3. Adanya dukungan yayasan untuk pembangunan gedung kampus baru.

4. Adanya keinginan pengelola kampus membuat segmentasi topologi jaringan komputer.

5. Otonomi khusus PemKab Lombok Tengah memberikan dukungan moril dan materil.

6. Jumlah mahasiswa makin tahun semakin bertambah

\section{Threat - Ancaman sebagai berikut:}

1. Perubahan teknologi yang cepat berpengaruh dalam pengembangan infrastruktur jaringan komputer.

2. Teknologi jaringan komputer yang baru terus berkembang dengan cepat.

3. Ancaman keamanan/serangan terhadap sistem informasi dan teknologi informasi jaringan komputer.

4. Mobilitas/perpindahan civitas kampus yang tinggi.

5. Jumlah mahasiswa semakin meningkat setiap tahunnya dan bandwidth lokal menjadi berkurang disebabkan bertambahnya jumlah mahasiswa.

6. Penurunan performa jaringan komputer disebabkan civitas kampus yang semakin bertambah.

7. Penurunan performa jaringan disebabkan hardware yang sudah lama.

Berdasarkan hasil analisis SWOT untuk peyusunan strategi TI dari visi, misi dan strategi bisnis untuk mendukung perancangan infrastruktur jaringan komputer pada STMIK Lombok. Hasil dari analisis matrik SWOT, sebagai berikut:

Tabel 4. Hasil Matriks SWOT

\begin{tabular}{|c|c|c|}
\hline Ekterna & $\begin{array}{l}\text { Kekuatan } \\
\text { (Strenght) }\end{array}$ & $\begin{array}{l}\text { Kelemahan } \\
\text { (Weakness) }\end{array}$ \\
\hline $\begin{array}{l}\text { Peluang } \\
\text { (Opportu } \\
\text { nity) }\end{array}$ & $\begin{array}{l}\text { Strategi S-O } \\
\text { S01. Memperc } \\
\text { epat } \\
\text { pembangunan }\end{array}$ & $\begin{array}{l}\text { Strategi W-0 } \\
\text { W01. Mening } \\
\text { katkan } \\
\text { pemanfaatan }\end{array}$ \\
\hline
\end{tabular}




\begin{tabular}{|c|c|}
\hline 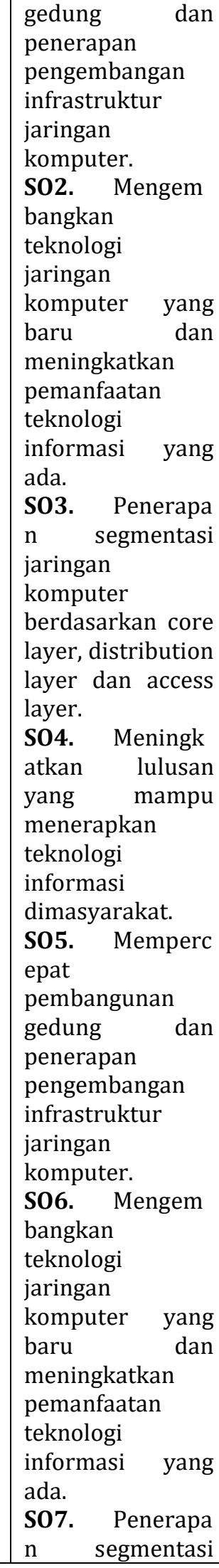 & $\begin{array}{l}\text { teknologi } \\
\text { informasi. } \\
\text { wo2. Memba } \\
\text { ngun gedung } \\
\text { perkuliahan, } \\
\text { laboratorium, } \\
\text { ruang } \\
\text { administrasi dan } \\
\text { ruang server } \\
\text { dengan } \\
\text { menyelaraskan } \\
\text { kebutuhan } \\
\text { infrastruktur } \\
\text { jaringan } \\
\text { komputer. } \\
\text { W03. Penamb } \\
\text { ahan komputer } \\
\text { diruang } \\
\text { perkuliahan } \\
\text { dengan akses } \\
\text { internet. } \\
\text { W04. Implem } \\
\text { entasi 10 sistem } \\
\text { informasi yang } \\
\text { belum berjalan. } \\
\text { wo5. Penyedi } \\
\text { aan pelayanan } \\
\text { wifi untuk } \\
\text { civitas kampus. } \\
\text { Wo6. Menjadi } \\
\text { kan laboratorium } \\
\text { yang berfungsi } \\
\text { sebagai } \\
\text { penunjang } \\
\text { pendidikan, } \\
\text { penelitian dan } \\
\text { pengabdian } \\
\text { pada } \\
\text { masyarakat. }\end{array}$ \\
\hline
\end{tabular}

\begin{tabular}{|c|c|c|}
\hline & $\begin{array}{l}\text { jaringan } \\
\text { komputer } \\
\text { berdasarkan core } \\
\text { layer, distribution } \\
\text { layer dan access } \\
\text { layer. }\end{array}$ & \\
\hline $\begin{array}{l}\text { Ancaman } \\
\text { (Threat) }\end{array}$ & $\begin{array}{l}\text { Strategi S-T } \\
\text { ST1. Penerapa } \\
\text { n teknologi } \\
\text { infrastruktur } \\
\text { jaringan } \\
\text { komputer terbaru } \\
\text { dengan } \\
\text { mempertimbangk } \\
\text { an spesifikasi } \\
\text { hardware } \\
\text { jaringan } \\
\text { komputer yang } \\
\text { ditawarkan. } \\
\text { ST2. Skalabilit } \\
\text { as diser } \\
\text { disesuaikan } \\
\text { dengan } \\
\text { kemampuan } \\
\text { skalabilitas } \\
\text { hardware } \\
\text { jaringan } \\
\text { komputer yang } \\
\text { digunakan. } \\
\text { ST3. Penerapa } \\
\text { n sistem } \\
\text { keamanan sistem } \\
\text { informasi dan } \\
\text { teknologi } \\
\text { informasi } \\
\text { (infrastruktur } \\
\text { jaringan } \\
\text { komputer) } \\
\text { seperti firewall } \\
\text { dan lain-lain. } \\
\text { ST4. Mengem } \\
\text { bangkan } \\
\text { teknologi } \\
\text { jaringan } \\
\text { komputer yang } \\
\text { baru } \\
\text { meningkatkan } \\
\text { pemanfaatan } \\
\text { teknologi } \\
\text { jaringan } \\
\text { komputer yang } \\
\text { ada. rT5. Pembaha } \\
\text { ruan }\end{array}$ & $\begin{array}{l}\text { Strategi W-T } \\
\text { WT1. Penamb } \\
\text { ahan jumlah } \\
\text { access point. } \\
\text { WT2. Penemp } \\
\text { atan dan } \\
\text { pembangunan } \\
\text { ruang server } \\
\text { dikhususkan } \\
\text { untuk keamanan } \\
\text { sistem informasi } \\
\text { dan teknologi } \\
\text { informasi. } \\
\text { WT3. Memper } \\
\text { cepat } \\
\text { pembangunan } \\
\text { gedung dan } \\
\text { menentukan } \\
\text { pemilihan } \\
\text { keamanan } \\
\text { sistem informasi } \\
\text { dan teknologi } \\
\text { informasi } \\
\text { (infrastruktur } \\
\text { jaringan } \\
\text { komputer). } \\
\text { WT4. Penamb } \\
\text { ahan komputer } \\
\text { diruang } \\
\text { perkuliahan dan } \\
\text { penambahan } \\
\text { laboratorium. } \\
\text { WT5. Memper } \\
\text { hatikan } \\
\text { spesifikasi } \\
\text { hardware } \\
\text { jaringan } \\
\text { komputer untuk } \\
\text { pengukuran } \\
\text { tingkat skalabilitas } \\
\text { perangkat yang } \\
\text { ditawarkan. } \\
\text { WT6. Penerap } \\
\text { an teknologi } \\
\text { komputer } \\
\text { terbaru seperti }\end{array}$ \\
\hline
\end{tabular}




\begin{tabular}{|c|c|c|}
\hline & $\begin{array}{l}\text { infrastruktur } \\
\text { hardware } \\
\text { jaringan } \\
\text { komputer untuk } \\
\text { hardware yang } \\
\text { sudah lama. }\end{array}$ & $\begin{array}{l}\text { VLAN (Virtual } \\
\text { LAN) } \\
\text { WT7. Penerap } \\
\text { an subnetting IP } \\
\text { address } \\
\text { berdasarkan } \\
\text { kebutuhan user } \\
\text { yang digunakan } \\
\text { WT8. Mening } \\
\text { katkan } \\
\text { pemanfaatan } \\
\text { teknologi } \\
\text { informasi } \\
\text { (infrastruktur } \\
\text { jaringan } \\
\text { komputer). } \\
\text { WT9. Mening } \\
\text { katkan } \\
\text { sumberdaya } \\
\text { manusia. } \\
\text { WT10. Mengan } \\
\text { alisis kebutuhan } \\
\text { user dimasa } \\
\text { mendatang. }\end{array}$ \\
\hline
\end{tabular}

\section{KESIMPULAN DAN SARAN}

Kesimpulan dari penelitian ini adalah analisis kebutuhan infrastruktur jaringan komputer, sebagai berikut:

1. Menginginkan adanya segmentasi jaringan komputer yaitu core, distribution, access agar dalam manajemen jaringan, penanganan policy/security lebih mudah ditangani terkait strategi SO3 tentang penerapan segmentasi jaringan komputer dan strategi ST1 tentang penerapan teknologi infrastruktur jaringan komputer terbaru dengan mempertimbangkan spesifikasi hardware yang ditawarkan.

2. Menginginkan adanya sebuah skalabilitas yang baik jika terjadi penambahan gedung kampus baru terkait strategi ST2 tentang skalabilitas user disesuaikan dengan kemampuan skalabilitas hardware teknologi informasi yang digunakan dan strategi WT5 tentang memperhatikan spesifikasi hardware jaringan komputer untuk pengukuran tingkat skalabilitas perangkat yang ditawarkan.

3. Menginginkan adanya performa jaringan komputer yang maksimal karena bisa membantu proses bisnis organisasi terkait strategi ST1 tentang penerapan teknologi infrastruktur jaringan komputer terbaru dengan mempertimbangkan spesifikasi hardware jaringan komputer yang ditawarkan dan strategi ST5 tentang pembaharuan infrastruktur hardware jaringan komputer untuk hardware yang sudah lama.

4. Menginginkan keamanan dari serangan jaringan internet dan serangan jaringan lokal terkait strategi ST3 tentang penerapan sistem keamanan SI/TI (infrastruktur jaringan komputer) seperti firewall dan strategi WT3 tentang mempercepat pembangunan gedung, menentukan pemilihan keamanan SI/TI (infrastruktur jaringan komputer).

5. Menginginkan penambahan wireless disetiap lantai terkait strategi W05 dan WT1 tentang penyediaan wifi untuk civitas kampus dan penmabahan access point pada setiap gedung.

6. Menginginkan adanya penerapan teknologi jaringan terbaru terkait strategi WT6 tentang penerapan teknologi jaringan seperti VLAN (Virtual LAN).

7. Laboratorium yang perlu dikembangkan terkait strategi W02 dan strategi WT3 tantang pembangunan/penambahan ruang laboratorium antara lain: 1). Lab jarkom dan sistem operasi, 2). Lab pemrograman, 3). Lab multimedia dan desain grafis, 4). Lab komputer dasar dan aplikasi, 5). Lab hardware dan software.

8. Setiap ruang perkuliahan terdapat komputer yang digunakan untuk dosen mengajar yang terkait strategi W03 tentang penempatan komputer pada ruang perkuliahan dan strategi WT3 tantang penambahan komputer diruang perkuliahan.

9. Jumlah port pada router ataupun switch dan perangkat yang lain sudah disesuaikan dengan perangkat jaringan terkait strategi WT5 tentang memperhatikan spesifikasi hardware jaringan komputer untuk pengukuran tingkat skalabilitas perangkat yang ditawarkan dan strategi ST1 tentang penerapan teknologi infrastruktur jaringan komputer terbaru dengan mempertimbangkan spedifikasi hardware yang ditawarkan.

10. Ketersediaan IP address yang sesuai kebutuhan penggguna, sehingga jika terjadi penambahan note jaringan komputer yang baru terkait strategi WT7 tentang penerapan subnetting IP address berdasarkan kebutuhan user yang digunakan. 


\section{Daftar Pustaka:}

[1] A. Jogiyanto, HM; Willy, Sistem Tatakelola Teknologi Informasi. Yogyakarta: Penerbit Andi, 2011.

[2] E. Hadi, W; Rosidi, Abidarin; Lutfi, Analisis Pemodelan AE untuk Mendukung SI Akademik dengan TOGAF (AMIK AMIKOM Surakarta). Yogyakarta: STMIK Amikom Yogyakarta, 2013.

[3] A. Sadewo, Perancangan Infrastruktur Jaringan Komputer Perum Pegadaian Kantor Wilayah Yogyakarta. Yogyakarta: Magister Teknologi Informasi, Universitas Gadjah Mada, 2013.

[4] F. Rangkuti, Analisis SWOT Teknik Membedah Kasus Bisnis: Cara perhitungan Bobot, Rating dan OCAI. Jakarta: PT. Gramedia, 2004.

[5] Z. Nisak, "ANALISIS SWOT UNTUK MENENTUKAN STRATEGI KOMPETITIF," J. Ekbis, 2003.

[6] S. Noor, "PENERAPAN ANALISIS SWOT DALAM MENENTUKAN STRATEGI PEMASARAN DAIHATSU LUXIO DI MALANG (Studi Kasus Pada PT. Astra International Tbk.-Daihatsu Malang)," J. INTEKNA, no. 2, pp. 102-209, 2014.
[7] H. H. Saragih, Rencana Strategis Teknologi Informasi (IT) dan Sistem Informasi (IS) Pada Proses Bisnis Perusahaan. Yogyakarta: Graha Ilmu, 2014.

[8] Bakti, W., Imtihan, K., \& Pardiansyah, A. S. (2018). Proxy Server dan Management Bandwidth Jaringan Komputer Menggunakan Mikrotik RB952Ui5ac2nD (Studi Kasus MA Ishlahul Ikhwan Nahdlatul Wathan Mispalah Praya). Jurnal Informatika dan Rekayasa Elektronik, 1(1), 44-49.

[9] Fadli, S., \& Imtihan, K. (2018). ANALISIS DAN PERANCANGAN SISTEM ADMINISTRASI DAN TRANSAKSI BERBASIS CLIENT SERVER. Jurnal Informatika dan Rekayasa Elektronik, 1(2), 7-14.

[10]Pitriyawati, M., \& Imtihan, K. (2018). Sistem Informasi Kenaikan Pangkat Karyawan Pada Dinas Pekerjaan Umum (PU) Dan Energi Sumber Daya Mineral (ESDM) Kabupaten Lombok Tengah.Jurnal Manajemen Informatika dan Sistem Informasi, 1(1), 3138. 